\title{
Specific and Holistic Predictors of Sprint Front Crawl Swimming Performance
}

\author{
by \\ Marek Strzała1 , Arkadiusz Stanula², Piotr Krężałek ${ }^{3}$, Wojciech Rejdych ${ }^{2}$, \\ Jakub Karpiński², Marcin Maciejczyk ${ }^{4}$, Artur Radecki-Pawlik ${ }^{5}$
}

\begin{abstract}
The aim of the study was to examine the impact of selected water-and dry-land predictors of 50-m front crawl performance among 27 male swimmers aged $19.3 \pm 2.67$ years. The following water tests were performed: front crawl tethered arm stroking in a water flume (flow velocity: $0.9 \mathrm{~m} \cdot \mathrm{s}^{-1}$ ) and leg tethered flutter kicking in a swimming pool. Anaerobic tests on dry land included arm cranking and a set of 10 countermovement jumps. The maximal and average forces generated by legs in tethered swimming ( $F_{l \max }$ and $F_{l \text { ave }}$ ) turned out to be the strongest predictors of sprint swimming aptitude. These values were strongly correlated with total speed $\left(V_{\text {totalo }}\right)(r=0.49, p<0.05$ and $r=0.54, p<$ 0.01 , respectively), start, turn, and finishing speed ( $\left.V_{\text {STF }}\right)(r=0.60, p<0.01$ and $r=0.67, p<0.01$, respectively). The relationship of $F_{l \text { max }}$ and $F_{l a v e}$ with surface speed ( $\left.V_{\text {surface}}\right)$ was moderate $(r=0.33$, non-significant and $r=0.41, p<0.05$, respectively). The maximal force generated by arms $\left(F_{a} \max \right)$ during flume tethered swimming significantly influenced $V_{\text {surface }}$ and $V_{\text {totalas }}\left(0.51, p<0.01\right.$ and $0.47, p<0.05$, respectively). Its relationship with $V_{\text {STF }}$ was close to significant $(0.36$, $p=0.07)$. Upper and lower limb dry-land tests showed lower and more holistic relationships with the 50-m front crawl race, however, being a good complement to overall fitness assessment. Specific in-water evaluation, especially the newly prepared flutter kicking test, as well as dry-land tests, can be applied to regularly monitor progress in swimming training, and to identify talented swimmers.
\end{abstract}

Key words: strength, test, power, movement velocity, biomechanics.

\section{Introduction}

Today, competitive swimmers undergo many different laboratory- and pool-based tests aiming to evaluate their physical development. Similar testing methods are used for talent identification and, thereafter, for athletes' progression assessment (Mitchell et al., 2018; Tanner and Gore, 2013).

The level of strength or power generated by an athlete, or the total work performed in a given test are considered, as in other sports, predictors of swimming results (Inbar et al., 1996;
Stager and Coyle, 2005). In practice, tests used to register these indicators vary. They can be divided into specific tests, performed in water with the use of swimming strokes, and general tests, conducted in dry-land conditions. Some of them, despite being carried out in dry-land conditions, may be indicative of generally favourable properties of a swimmer's body, e.g., upper or lower limb ability to produce power. In fact, the general physiological ability of upper limb anaerobic power production tested in an arm cranking test showed a significant relationship with sprint front

1 - Department of Water Sports; Faculty of Physical Education and Sport, University of Physical Education, Kraków, Poland.

2 - Department of Swimming and Water Rescue; Institute of Sport Sciences, The Jerzy Kukuczka Academy of Physical Education,

Katowice, Poland.

3 - Department of Physiotherapy; Faculty of Rehabilitation, University of Physical Education, Kraków, Poland.

4 - Department of Physiology and Biochemistry; Faculty of Physical Education and Sport, University of Physical Education,

Kraków, Poland.

5 - Faculty of Civil Engineering; Cracow University of Technology, Kraków, Poland.

Authors submitted their contribution to the article to the editorial board.

Accepted for printing in the Journal of Human Kinetics vol. 78/2021 in April 2021. 
crawl swimming (Hawley and Williams, 1991; Hawley et al., 1992; Rohrs and Stager, 1991; Strzała and Tyka, 2009). Even less swimming-specific isometric tests of upper limbs revealed their impact on swimming results along with maturity; later, however, when the athlete achieves a higher level of skills, this effect disappears (Garrido et al., 2012; Strzała et al., 2019). Similar considerations can be made for dry-land lower limb testing with the use of countermovement jumps (Amaro et al., 2017; Cronin et al., 2007; Garrido et al., 2010; Keiner et al., 2015; Strzała et al., 2019; West et al., 2011).

It is believed, though, that to better explain the level of a swimmer's preparation, the evaluation should primarily include an assessment of their abilities in water conditions. Benefits of specific measurements in water to evaluate, monitor, and adjust training programs were noticed by Christensen and Smith (1987) who mentioned that 'in-water testing may be a valuable tool for coaching swimmers'. Sharp and Costill (1982) suggested the use of 'measuring and training devices during a dynamic action that most closely resembles the movement of actual swimming'.

Nevertheless, the selection of assessment indicators measured in the water is at least partly related to the activities involved in swimming competitions. Therefore, these indicators refer to race analysis (Lipinska and Hopkins, 2017; Morais et al., 2019; Strzała et al., 2015; Veiga et al., 2016), spatial and temporal movement analysis (Mooney et al., 2017; Strzała et al., 2017; Wadrzyk et al., 2021; Washino et al., 2019), or somatic and physiological traits (Barbosa et al., 2019; Kalva-Filho et al., 2017; Morais et al., 2018; Strzała et al., 2019) as directly influencing a swimmer's ability to produce power, propulsion force, and swimming speed (Barbosa et al., 2015; Loturco et al., 2016; Olstad et al., 2017). When looking for appropriate tests of the power producing ability, resulting in propulsion force generation, one can state that tests of the upper extremities (Dominguez-Castells et al., 2013; Morouço et al., 2011, 2015; Santos dos et al., 2012) or whole body swimming are often chosen. These measurements were usually performed in tethered (Amaro et al., 2014; Costill et al., 1986; Dopsaj et al., 2000; Morouço et al., 2014) or semi-tethered swimming conditions (Dominguez-Castells et al., 2013; Vorontsov et al., 1999). In turn, propulsion force generation with the use of lower limbs was rarely evaluated (Morouço et al., 2011, 2015; Vorontsov et al., 1999), although in sprint swimming, their participation in generating propulsion is significant (Gourgoulis et al., 2014; Morris et al., 2016); it seems even more important for the whole body stabilisation during intensive arms stroking (Gatta et al., 2012; Watkins and Gordon, 1982). In addition, leg strength can have a significant impact on the speed of locomotion besides clean full stroke swimming zones during a $50-\mathrm{m}$ freestyle race, where the start time, defined as time to $15 \mathrm{~m}$, has been reported as a critical component of the overall swimming performance (West et al., 2011). An influence of leg strength on turn zone speed was also observed (Cronin et al., 2007).

In the context of these arguments, the purpose of the present study was to examine the impact of selected indicators, related directly to the stroke and distance swim activity of 50-m sprint front crawl swimming: (a) propulsive indicators of arm stroking only, measured during front crawl tethered swimming in a water flume; (b) lower limb propulsion generated by flutter kicks while swimming on tethers in stagnant water in a swimming pool.

Following the experimental design of swimming test conditions (see the Methods section), we aimed to focus on the following issues: (a) standing water, in which the conditions for propulsive stroking of the arms are different than during free swimming; (b) avoidance of bumping the feet with the cable suspended just above them, or a problematic lifting of the lower body in order to increase the inclination angle of the tethering cable.

Bearing in mind the different impact of indicators obtained under distinct conditions (water vs. dry-land) on swimming performance, we wanted to investigate whether the dry-land indicators chosen for the study observation would constitute a good complement to the assessment of 50-m front crawl performance. Two holistic anaerobic work tests were selected: (a) use of upper extremities in arm cranking; and (b) a series of countermovement jumps.

We assumed that the results of the chosen specific water tests would be good predictors of sprint front crawl swimming performance. In addition, dry-land tests should well complement the assessment of the swimmers' anaerobic and 
strength conditioning.

In order for the selected indicators to be considered more predictive, we assessed the development of sports talent rather than performed maturational development analyses with the age factor controlled for (Dormehl et al., 2016; Mitchell et al., 2018; Strzała et al., 2019).

\section{Methods}

\section{Participants}

Overall, 27 male swimmers were recruited from a sport swimming-oriented high school and two university swimming clubs. The basic demographic characteristics of the participants were as follows: age: $19.3 \pm 2.67$ years, body height: $184.0 \pm 6.82 \mathrm{~cm}$, body mass: $78.5 \pm 12.06 \mathrm{~kg}$. All participants had licenses from the Polish Swimming Federation and were healthy, as required by the inclusion criteria. The selected group competed at a regional (4 swimmers), national (19), or international level (4). Their personal best results in the $50-\mathrm{m}$ freestyle short course amounted to $77.9 \%, 83.9 \%$, and $90.8 \%$ of senior swimmers' world record, respectively.

Participants trained twice a day, 6 days a week. Any injury that could affect the results of the study was considered an exclusion criterion. All swimmers (or their parents) signed informed consent to take part in the research. The study was approved by the University Bioethics Committee at the Jerzy Kukuczka Academy of Physical Education in Katowice (no. 8/2018).

\section{Tethered Swimming}

The upper extremity test, 20-s all-out front crawl stroking, was performed on a tether in a water flume. To ensure adequate buoyancy of the lower limbs, the swimmer was equipped with two buoys, placed between the thighs and ankles. Additionally, to prevent the buoy from falling out, the swimmer's ankles were wrapped with adhesive tape. The swimmer was connected to a steel pole with a 5.65-m steel cable (with a waist belt) and a dynamometer (recording at $100 \mathrm{~Hz}$ ) (Figure 1). The point of fixing the dynamometer to the pole was $0.49 \mathrm{~m}$ above the water surface. The flow velocity of water in the swimming flume was set to $0.9 \mathrm{~m} \cdot \mathrm{s}^{-1}$. The average stroke rate was calculated on the basis of stroke cycles recorded during the 20-s period by a camcorder (JVC GCPX100BE, Japan), working at the sampling rate of $100 \mathrm{fps}$. The observed number of cycles during the
$20 \mathrm{~s}$ was converted to cycles $\mathrm{min}^{-1}$. For each participant, three main indices were calculated during the 20-s period: (a) maximum value of arm force $-F_{a} \max (\mathrm{N})$; (b) average value of arm force $-F_{a}$ ave $(\mathrm{N})$; and (c) average arm impulse per cycle $-I_{a}$ $(\mathrm{N} \cdot \mathrm{s})$ (calculated as the integral of force over a period of time containing all full cycles which appeared during the 20-s recording, divided by the number of these cycles $-\mathrm{n}$ ):

$$
I_{a}=\frac{\int_{t_{0}}^{t_{1}} F d t}{n}
$$

where: $t_{0}$ - beginning of the first full cycle, $t_{1}-$ ending of the last full cycle in the 20-s period.

In the lower extremity test, towing force was measured during tethered flutter kicking (front crawl) in a pool over $20 \mathrm{~s}$. The test was carried out with the support of a kickboard (Figure 2 ). The steel cable which the swimmer was attached to during the test formed two equal 3-m arms of a triangle. The cable end was attached to the start block, then passed through a grommet in the swimmer's belt, and was attached to another starting block via a force transmitter. The distance between the fastening points on the starting blocks was $2.2 \mathrm{~m}$.

Swimmers were asked to swim towards the point visible in front of them, located in the axis of symmetry of the system. The geometry of the measuring system was the same for all swimmers, thus the proportion of force registered by the force transducer $F_{m e s}$ and the propulsion force generated by participants was also the same, in accordance with the formula:

$$
F=2 F_{m e s} \cos \left[\arcsin \left(\frac{1.1}{3}\right)\right]=1.86 F_{m e s}
$$

In this test, two main indices were calculated during the 20-s period: (a) maximum value of leg force $-F_{l} \max (\mathrm{N})$; (b) average value of leg force $-F_{\text {lave }}(\mathrm{N})$.

\section{Dry-Land Maximal Anaerobic Power}

A 20-s upper extremity test, arm-cranking, was performed in a sitting position, with the use of a custom designed ergometer (834E-Ergomedic, Monark, Sweden). The ergometer braking force was set for each individual at $4.5 \%$ of body mass. Average work of arms: $W_{c r a}(\mathrm{~J})$, as well as maximal power generated by arms: $P_{\text {cra }} \max (\mathrm{W})$ were measured during this test. Also, the values of these 
indices in relation to body mass were calculated and analysed: $W_{\text {cra rel }}\left(\mathrm{J} \cdot \mathrm{kg}^{-1}\right)$ and $P_{\text {cra rel } \max }\left(\mathrm{W} \cdot \mathrm{kg}^{-1}\right)$. Prior to the test, swimmers underwent a 4-min warm-up, which consisted of continuous arm cranking (cadence: $90 \cdot \mathrm{min}^{-1}$ ) at a minimal workload. In half of this time and close to the end of the $4 \mathrm{~min}$, short sprints lasting $5 \mathrm{~s}$ were performed against heavier resistance that still allowed the participants to crank at the cadence of 90-100· $\mathrm{min}^{-1}$ (Inbar et al., 1996).

The lower extremity test consisted of a set of 10 countermovement jumps performed on a force plate (AMTI BP 400600, USA) rigidly fixed to the laboratory floor. The frequency of jumps was imposed using a metronome - one jump every $2 \mathrm{~s}$. At the beginning of the test, the athlete stood upright on the force plate with their weight evenly distributed between both feet. Hands were placed on the hips throughout the whole test to eliminate their contribution to energy generation. Work generated in a single jump - $W_{\text {СM }}(\mathrm{J})$, averaged over the 10 jumps, was taken as an absolute indicator of anaerobic muscle system motor capabilities. Average elevation of the centre of mass - $h(\mathrm{~cm})$ - in the 10 jumps was considered an indicator of motor abilities relative to body mass. The test was performed after a 5-min dynamic warm-up, which included dynamic stretching, progressive intensity shuttle runs, and bodyweight squats (Mitchell et al., 2018).

\section{Sprint Swimming Race}

The all-out swimming 50-m front crawl race was conducted in a 25-m swimming pool which met the International Swimming Federation standards. Time measurement was performed using an automatic timing device (Omega, Switzerland). In this race, swimmers competed in pairs. Pairs were selected in accordance with similar personal best results. Participants were asked to perform in-the-water starts, which made it easier to shorten the underwater swimming phase after the start to $8 \mathrm{~m}$.

The surface stroke rate - SR surface (cycles $\cdot \mathrm{min}^{-1}$ ) - was determined by 2 camcorders (JVC GC-PX100BE, Japan) working at the sampling rate of $100 \mathrm{fps}$. One camcorder for each swimmer recorded their movements from the side view. The $S R$ surface was taken as an average from 6 stroke cycles ( 3 consecutive cycles of the middle section of the first and second laps). The camcorders were placed close to the middle point $(12.5 \mathrm{~m})$ of the pool length and attached to tripods with a rotating head.

The stroke length $(S L)$ calculation was based on the data gathered in 9-m sectors of the distance of $50 \mathrm{~m}$, during both laps (between the $8^{\text {th }}$ and $17^{\text {th }} \mathrm{m}$ for the first lap, and between the $33^{\text {rd }}$ and $42^{\text {nd }} \mathrm{m}$ for the second lap). For the purpose of this measurement, two more JVC GC-PX100BE camcorders (sampling rate: $100 \mathrm{fps}$ ) were used. The camcorders were located on tripods standing on the pool deck. Recordings from these two cameras were synchronised with a flash light triggered by the Omega electronic starting device. The JVC camcorders filmed each swimmer's head when it crossed the 8-, 17-, 33-, and 42-m lines of the distance.

The recordings allowed to calculate the average time needed to complete the 9-m sectors $(\Delta t)$ and thus to establish the average 18-m surface swimming speed $\left(V_{\text {sufface }}\right)$. SL was calculated as a quotient of the average speed for the $18-\mathrm{m}$ and stroke rate $\left(S R_{\text {surface }}\right): S L=V / S R_{\text {surface }}(\mathrm{m})$. The sum of the duration of swimming in the 8-m zones of start, turn, and finish was used to determine the 32-m average swimming speed $\left(V_{\text {STF }}\right)$. Then, the time achieved by swimmers in the entire 50-m race was taken to calculate the swimming speed $\left(V_{\text {total }}\right)$.

All participants underwent familiarisation with the tethered swimming during a warm-up session before both tethered tests. Validation of the novel tethered swimming procedures was conducted; the intra-class correlation coefficient $(2,1)$ value equalled 0.997 (95\% confidence interval: 0.988-0.999) for the upper extremity test and 0.997 (95\% confidence interval: 0.988-0.999) for the lower extremity test. Relative reliability was investigated using intra-class correlation coefficients (model $2,1)$ with a $95 \%$ confidence interval. All recorded data were constantly displayed on a laptop screen and stored on a hard disk. The data were processed by signal processing software (Max 6.0; JBA, Poland) and filtered through a $4.5-\mathrm{Hz}$ low-pass filter. The 50-m free front crawl race and tethered front crawl tests were preceded by a warm-up selected by each athlete, similar to the one carried out before a competition, including at least 1000-m swimming with front crawl and other techniques. Statistical Analyses

The normality, homoscedasticity, and independency of the data assumptions were examined with the Kolmogorov-Smirnov, Levene, and Durbin-Watson tests, respectively. One-way 
repeated measures analysis of variance (ANOVA) and Tukey honestly significant difference (HSD) post-hoc tests were used to describe the comparison of average speeds $\left(V_{\text {total5o, }} V_{\text {surface, }} V_{\text {STF }}\right)$. To exclude individual swimmers' features of maturity, partial correlations (controlled for age) between particular speeds ( $\left.V_{\text {total5o, }} V_{\text {surface }}, V_{\text {STF }}\right)$ and all indices were calculated.

To compare stroke rate data (SR of $50-\mathrm{m}$ free front crawl swimming and $S R$ of tethered swimming), the Student's t-test was applied for normally distributed data and equal variances. To further evaluate mean differences, Cohen's effect size (d) was calculated to express differences relative to the pooled standard deviation. The magnitude of differences between groups was expressed as standardised mean differences (Cohen's d, effect sizes). The criteria to interpret the effect size magnitude were as follows: trivial $(0.00-$ $0.19)$, small (0.20-0.59), moderate (0.60-1.20), and large $(>1.20)$ (Hopkins, 2002). Additionally, the Pearson linear relationship was computed between the speeds ( $\left.V_{\text {totallo, }} V_{\text {surface, }} V_{\text {STF }}\right)$ of the 50-m race and between maximal and average force results of tethered swimming.

Statistical significance was set as $p \leq 0.05$. All tests were performed with the Statistica ver. 12 software (StatSoft, Inc.).

\section{Results}

The all-out 50-m sprint performance results are presented as average speeds for the whole distance $-V_{\text {totals0 }}\left(1.86 \pm 0.07 \mathrm{~m} \cdot \mathrm{s}^{-1}\right)$, surface front crawl swimming zones $-V_{\text {surface }}(1.79 \pm 0.06$ $\mathrm{m} \cdot \mathrm{s}^{-1}$ ), and the remaining zones of the race (start, turn, and finish zones) $-V_{\text {STF }}\left(1.91 \pm 0.07 \mathrm{~m} \cdot \mathrm{s}^{-1}\right)$. The calculated repeated measures ANOVA for these speeds showed a significant difference between them: $\mathrm{F}(2,52)=124.34 ; p<0.001$. Moreover, the Tukey HSD test revealed significant differences $(p$ $<0.001$ ) across the compared averages ( $V_{\text {totall50, }}$ $V_{\text {surface, }} V_{\text {STF }}$ (Figure 3). Both $V_{\text {surface }}$ and $V_{\text {STF }}$ presented a strong relationship with $V_{\text {totallon, as }}$ indicated by the Pearson correlation coefficient: $\mathrm{r}=$ $0.90, p<0.001$ and $\mathrm{r}=0.91, p<0.001$, respectively.

In the group of functional indices nonspecific for swimming, measured during a set of countermovement jumps, only the average value of absolute work in the 10 jumps - $W_{\text {CMJ }}(\mathrm{J})$ - was significantly correlated with $V_{\text {STF }}$ (Table 1). The relationships of this index with other speeds revealed significance for $V_{\text {totalso }}$ and lack of significance for $V_{\text {surface }}$ (Table 1). The $h(\mathrm{~cm})$, relative to the body mass index, did not correlate with the speed values obtained in the swimming test.

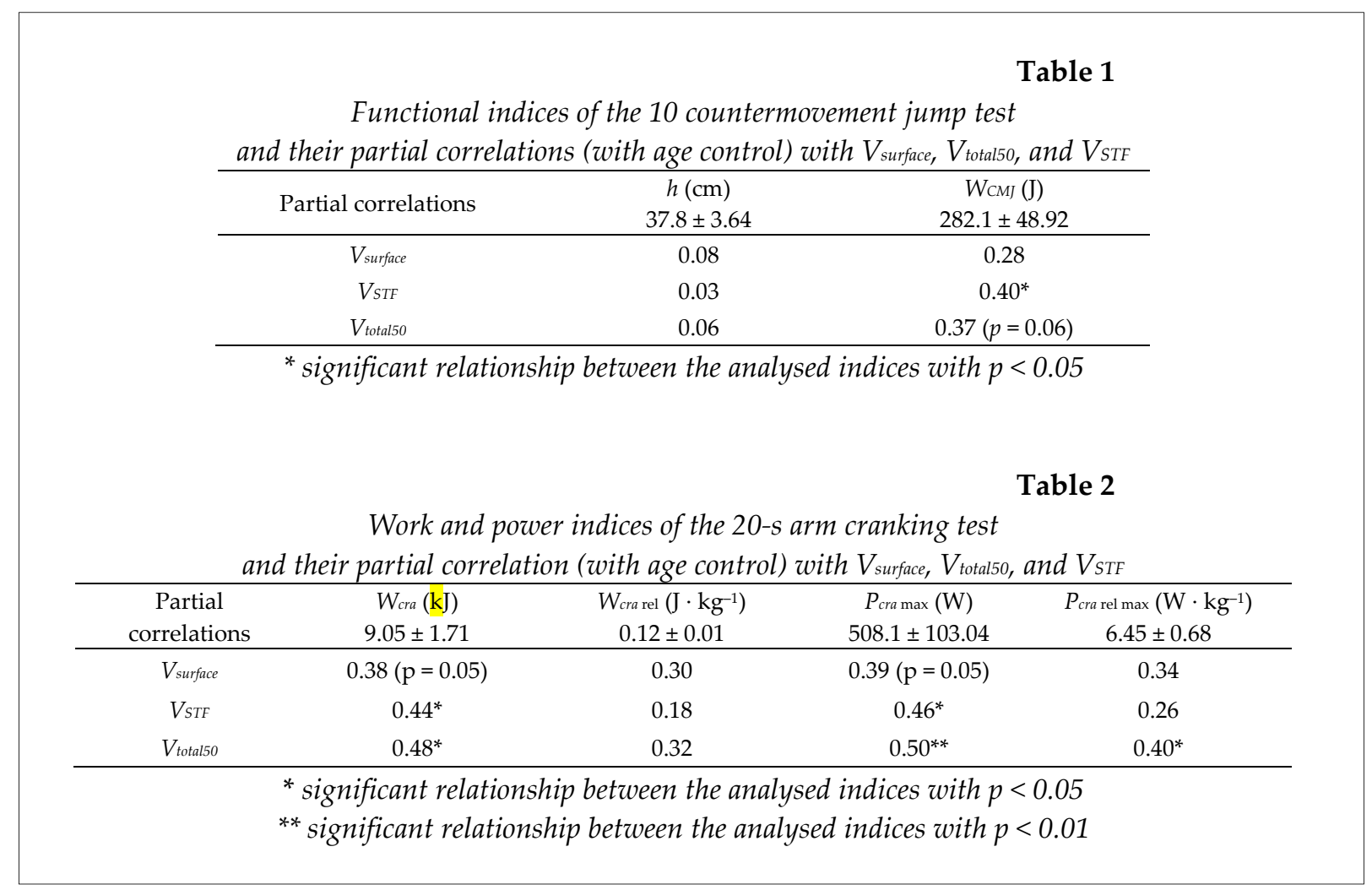




\section{Table 3}

Indices of tethered swimming with arm stroking only: maximal force ( $\left.F_{a \text { max }}\right)$, average force $\left(F_{a \text { ave }}\right)$, average impulse $\left(I_{a}\right)$; and with leg kicking only:

maximal force $\left(F_{l \max }\right)$ and average force $\left(F_{\text {lave }}\right.$ ). Partial correlations with age control between forces obtained for tethered swimming and $V_{\text {surface, }} V_{\text {total50, }}$ and $V_{\text {STF }}$

\begin{tabular}{cccccc}
\hline $\begin{array}{c}\text { Partial } \\
\text { correlations }\end{array}$ & $F_{a \max }(\mathrm{N})$ & $F_{a \text { ave }}(\mathrm{N})$ & $I_{a}(\mathrm{~N} \cdot \mathrm{s})$ & $F_{l \max }(\mathrm{N})$ & $F_{l \text { ave }}(\mathrm{N})$ \\
\hline$V_{\text {surface }}$ & $222.9 \pm 48.79$ & $62.2 \pm 9.30$ & $65.61 \pm 9.57$ & $131.5 \pm 37.28$ & $41.6 \pm 12.26$ \\
$V_{\text {STF }}$ & $0.51^{* *}$ & $0.36(p=0.07)$ & 0.33 & 0.33 & $0.41^{*}$ \\
$V_{\text {total50 }}$ & $0.36(p=0.07)$ & 0.24 & 0.18 & $0.60^{* *}$ & $0.67^{* *}$ \\
\hline
\end{tabular}

* significant relationship between the analysed indices with $p<0.05$

** significant relationship between the analysed indices with $p<0.01$

\section{Figure 1}

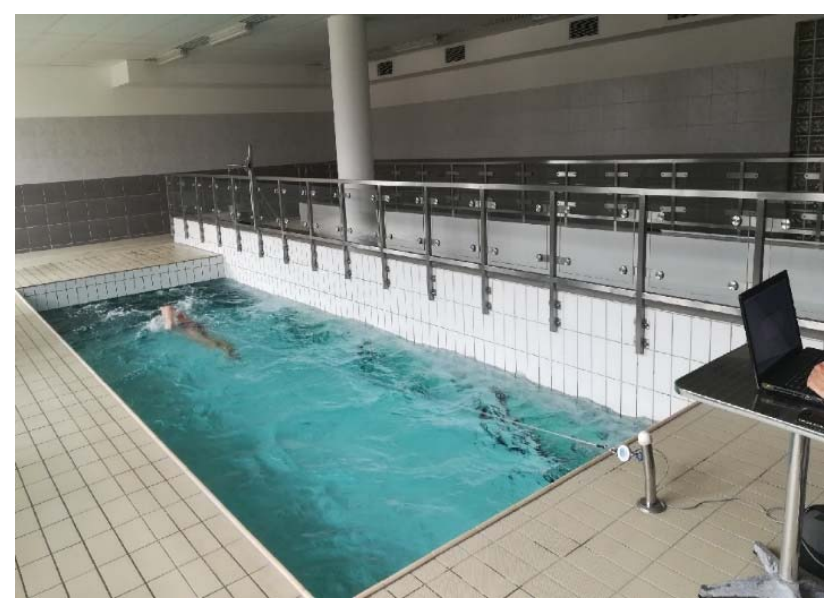

Measurement of force during a 20-s all-out tethered front crawl arm stroking test.

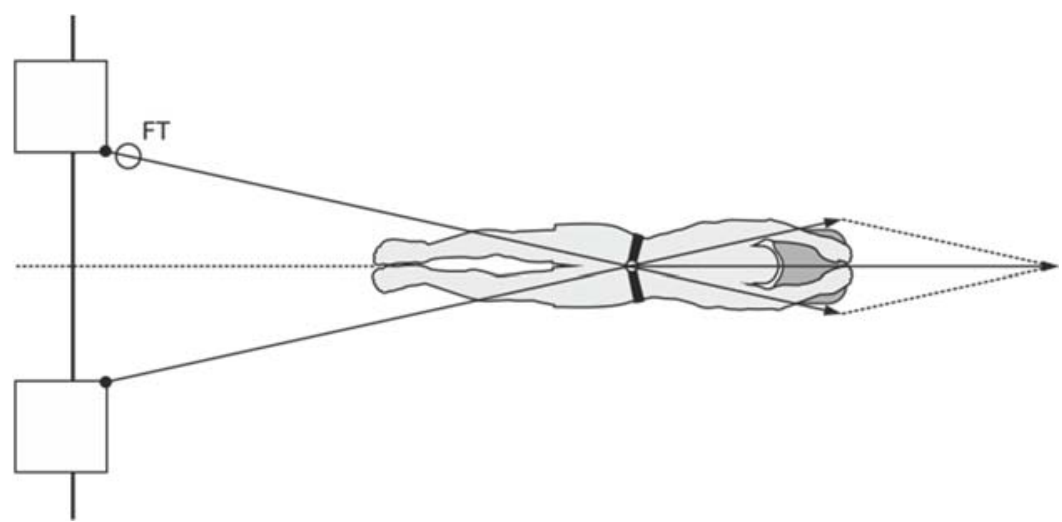

Figure 2

Measurement of force during a 20-s all-out tethered flutter kicking test (FT-force transmitter). 


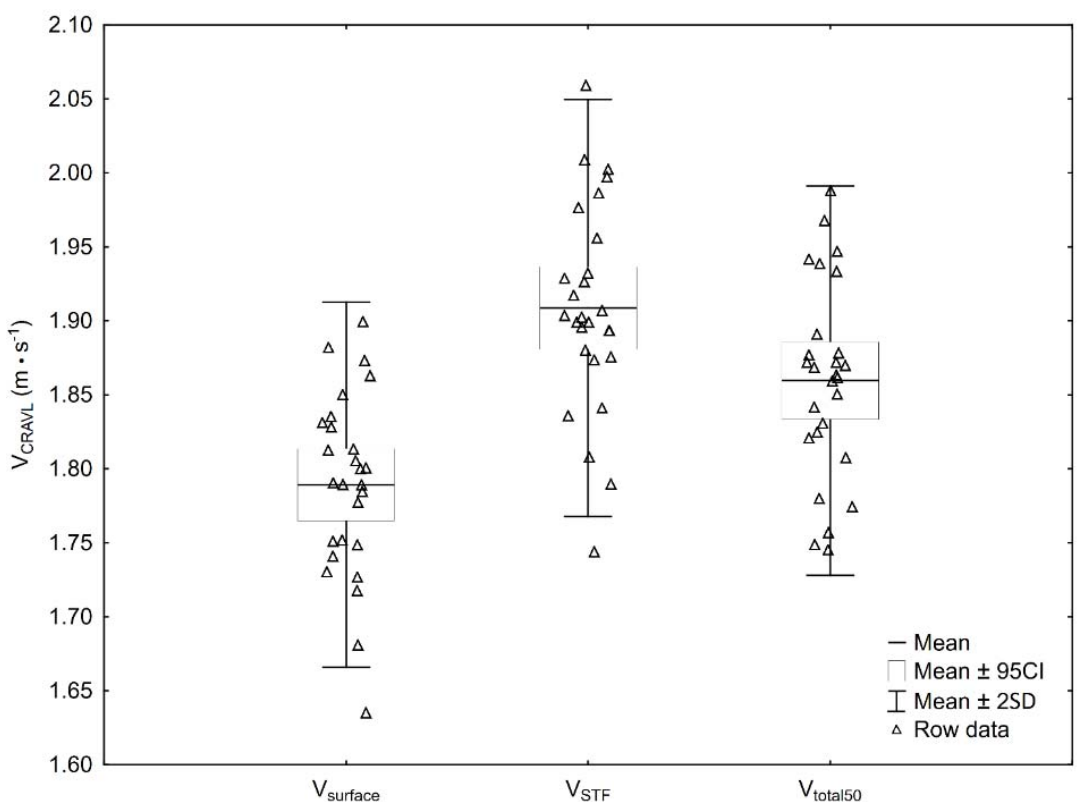

Figure 3

Speed in the particular zones of a 50-m front crawl race.

The non-specific work and power indices obtained in the anaerobic arm cranking test presented slightly greater dependence with each distinguished speed than the functional leg indices. The same refers to absolute work $-W_{\text {cra }}(\mathrm{J})$ - and maximal power - $P_{\text {cra } \max }(\mathrm{W})$. When these indices were expressed per kilogram of body mass, the partial correlation with speeds turned out low or negative and non-significant (Table 2).

The maximal force generated by the arms during flume tethered swimming ( $\left.\begin{array}{ll}F_{a} & \max \end{array}\right)$ significantly influenced $V_{\text {surface }}$ and $V_{\text {total50. Its }}$ relationship with $V_{S T F}$ was on the edge of significance. Similarly, only a moderate relationship was found between $F_{a}$ ave and $V_{\text {surface }}$ (Table 3). The strongest predictor of sprint swimming aptitude in the study was force $\left(F_{l \max }\right.$ and $F_{l}$ ave) generated by legs in tethered swimming, which correlated strongly with $V_{\text {total50 }}$ and $V_{S T F}$, and moderately with $V_{\text {surface }}$ (Table 3 ).

The value of the stroke rate kinematic index was also calculated for flume tethered arm stroking: $S R_{\text {flume }}=57.02 \pm 6.62$. This result was significantly higher (paired t-test: $\mathrm{t}_{(26)}=2.13, p=$ $0.04)$ in comparison with $S R_{\text {surface }}$ of the surface swimming zone: $54.8 \pm 5.93$ (Figure 4). The magnitude of these $S R$ indices difference was additionally checked using Cohen's effect size, and a small effect was noted $(\mathrm{d}=0.425)$. The kinematic $S L$ index did not correlate with $V_{\text {surface }}(1.98 \pm 0.21)$, while $S R_{\text {surface }}$ correlated significantly with $V_{\text {surface }}(\mathrm{r}$ $=0.50, p=0.02$ ).

The correlation between $F_{a \max }$ and $F_{a}$ ave was 0.61 $(p<0.01)$. It should be emphasised that the dependence between $F_{l \text { max }}$ and $F_{l}$ ave turned out very high: $0.80(p<0.001)$.

\section{Discussion}

In the present study, the strongest predictor of the sprint swimming aptitude was force ( $F_{l \text { max }}$ and $F_{l}$ ave) generated by legs in tethered swimming. Logically, this relationship was strongest when the body was moving partly under the surface of the water, with greater participation of the legs, i.e., in the STF zones. The influence of both $F_{l \text { max }}$ and $F_{l}$ ave indices on $V_{\text {totalso }}$ was still high 
and significant, although the relationship between them and $V_{\text {surface }}$ decreased to a moderate one. Swimming on a tether with the use of the flutter kick is rarely implemented in in-water strength testing in swimmers. This is because of the defects which may occur during testing, e.g., bumping the feet with the cable suspended just above them or problematic lifting of the lower body owing to the need to increase the tethering cable inclination angle. In our measurements, we avoided these problems using the triangular geometry of the cable lead, which was an innovative solution for the tethered test stand. Another advantage was that the swimmer adopted the body position routinely applied in training with continuous contact with the subject through the emerging head. Furthermore, in our opinion, the very high relationship between $F_{l \text { max }}$ and $F_{l \text { ave }}(0.80, p<0.001)$ in this test increases its potential to be used to assess sprint swimming abilities. This results from the fact that the performance time of $20 \mathrm{~s}$ requires not only instantaneous strength, but also the ability to maintain high average propulsion generation (Stager and Coyle, 2005). The average and maximum force values obtained in this work turned out to be slightly higher than those observed by Morouço et al. (2015), i.e., $35.1 \mathrm{~N}$ and $100.1 \mathrm{~N}$, respectively, or than the average force of $33.6 \mathrm{~N}$ measured in another study by Morouço et al. (2011). These differences are most likely related to the higher average age of the athletes in the present study and shorter duration of the test. In a study conducted by Vorontsov et al. (1999), during a kicking tethered test, subjects were instructed to exert maximal effort for 5-7 s. The force generated by legs among 18-year-olds in that measurement was $118.6 \mathrm{~N}$ and turned out slightly lower than the one registered in the present study in the strongest single kicks.

A lower level of dependence with $V_{\text {surface }}$ (close to significance) was obtained by analysing the impact of the propulsion by the arms $\left(F_{a}\right.$ ave $)$ measured in the swimming test in the water flume. Despite the higher dependence of $F_{a}$ max on $V_{\text {surface }}$

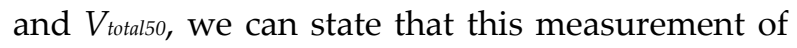
strength, limited by the lack of support for the legs, does not provide a full opportunity to explore specific sprinting abilities. The interpretation of the need for higher influence of $F_{a}$ ave on $V_{\text {sufface }}$ may be reinforced by the reported high dependence of the $S R_{\text {surface }}$ index on $V_{\text {surface }}(\mathrm{r}=0.50, p=0.02)$, i.e., the ability to perform even cyclic motions. Perhaps an additional difficulty in the sufficient generation of body propulsion by the upper limbs was caused by attaching tethers to the waist, flowing water and lack of the flutter kick support. These conditions probably led to a significant increase in $S R_{\text {flume }}$ (57.02 cycles $\cdot \mathrm{min}^{-1}$ ) compared with $S R_{\text {surface }}$ (54.8 cycles. $\mathrm{min}^{-1}$ ), and propulsion phases of both arms overlapping to a greater extent compared with whole body tether swimming, observed in other studies (Dominguez-Castells et al., 2013; Strzała et al., 2019). Less favourable conditions for generating propulsion force, occurring when swimming using only the arms, have already been found by other researchers as a result of an unstable trunk position (Watkins and Gordon, 1982), unfavourable changes in the wrist trajectory (Deschodt et al., 1999), reduction in the propulsive forces of the upper limbs (Morouço et al., 2015), and lesser swimming economy (Morris et al., 2016). It has already been suggested that a kick while front crawl swimming is a body stabiliser. The action of legs neutralises the reaction of the rest of the body to the arm action; as a result, it keeps the position of the trunk quite stable, which results in a more effective arm action (Lawrence, 1969; Prins and Murata, 2008).

We mentioned in the introduction that our tests of the force generated by the arms only in tethered conditions might be similar to those previously carried out (Dominguez-Castells et al., 2013; Morouço et al., 2011, 2015; Santos dos et al., 2012; Strzała et al., 2019; Vorontsov et al., 1999). However, these results could not be compared owing to different test conditions as we focused on stroking arms only in flowing water.

Nevertheless, this study noted a significant relationship between the indices of the anaerobic arm cranking test and swimming results, less expected than that of specific indices. This refers to the relationship of $W_{\text {cra }}$ with $V_{\text {totalso }}$ and $V_{\text {STF, }}$ and $P_{\text {cra }} \max$ with $V_{\text {totalso }}$ and $V_{\text {STF. }}$. However, these results coincide with those obtained by other researches (Hawley and Williams, 1991; Hawley et al., 1992; Rohrs and Stager, 1991; Strzała and Tyka, 2009). Probably, as we assumed, in order to assess athletes' progress in their holistic anaerobic properties, tests showing a physiological ability to generate power can be selected.

Functional indices measured during the set of countermovement jumps showed that the 
average absolute value of work obtained in the 10 jumps - $W_{C M J}(\mathrm{~J})$ - was significantly correlated with $V_{\text {STF }}$ and its correlation with $V_{\text {total50 }}$ was close to significant. Therefore, this test can be considered as a sufficient complement to the assessment of the general abilities in relation to the involvement of lower limbs during sprinting, especially in the zones of their increased propulsion. These observations corroborate previous reports (Cronin et al., 2007; Mitchell et al., 2018; Strzała and Tyka, 2009).

The aim of this study was to examine whether newly prepared specific water and dryland tests effectively distinguished between high and low performers in a group of swimmers of different ages. The measurements carried out indicate that the test of specific abilities of the lower limbs during the execution of the flutter kick propulsion movement was the best predictor of the aptitude to sprint front crawl swimming. Our research on sprint front crawl stroking of the arms refers to previous observations (Deschodt et al., 1999; Dominguez-Castells et al., 2013; Strzała et al.,
2020; Watkins and Gordon, 1982) which indicate that the separation of arm movements during feet immobilisation, with the lack of support for leg muscles and torso, may not be sufficient to reveal their full effectiveness.

Bearing in mind the present results and a scarce number of similar studies, one can state that to identify talents, cyclically monitor progress of swimming skills and improve them, the specific swimming skills test performed with the lower limbs can be used in the manner proposed in this study. Performing the flutter-kick test, partly redesigned, allowed an uncomplicated and reliable measurement of force, which facilitated a full focus on the task, i.e., generating force, without limiting the range of leg movement. This test should be applied alongside whole body tether swimming.

Selected dry-land tests, the arm cranking test and a set of 10 countermovement jumps, can be a good complement to the overall fitness assessment of upper and lower limbs in conditioning for sprint front crawl swimming.

\section{References}

Amaro NM, Marinho DA, Batalha N, Marques MC, Morouço P. Reliability of tethered swimming evaluation in age group swimmers. J Hum Kinet, 2014; 41: 155-162

Amaro NM, Marinho DA, Marques MC, Batalha NP, Morouço PG. Effects of dry-land strength and conditioning programs in age group swimmers. J Strength Cond Res, 2017; 31: 2447-2454

Barbosa AC, Valadão PF, Wilke CF, Martins F de S, Silva DCP, Volkers SA, Lima COV, Ribeiro JRC, Bittencourt NF, Barroso R. The road to 21 seconds: A case report of a 2016 Olympic swimming sprinter. Int J Sport Sci Coach, 2019; 14: 393-405

Barbosa TM, Bartolomeu R, Morais JE, Costa MJ. Skillful swimming in age-groups is determined by anthropometrics, biomechanics and energetics. Front Physiol, 2019; 10: 1-10

Barbosa TM, Morais JE, Marques MC, Costa MJ, Marinho DA. The power output and sprinting performance of young swimmers. J Strength Cond Res, 2015; 29: 440-450

Christensen C, Smith G. Relationship of maximum sprint speed and maximal stroking force in swimming. J Swim Res, 1987; 3: 18-20

Costill DL, Reifield F, Kirwan J, Thomas R. A computer based system for the measurement of force and power during front crawl swimming. J Swim Res, 1986; 2: 16-19

Cronin J, Jones J, Frost D. The relationship between dry-land power measures and tumble turn velocity in elite swimmers. J Swim Res, 2007; 17: 17-23

Deschodt J V., Arsac LM, Rouard AH. Relative contribution of arms and legs in humans to propulsion in 25m sprint front-crawl swimming. Eur J Appl Physiol Occup Physiol, 1999; 80: 192-199

Dominguez-Castells R, Izquierdo M, Arellano R. An updated protocol to assess arm swimming power in front crawl. Int J Sports Med, 2013; 34: 324-329

Dopsaj M, Matković I, Zdravković I. The relationship between 50m - freestyle results and characteristics of tethered forces in male sprint swimmers: A new approach to tethered swimming test. Facta Univ - Ser Phys Educ Sport, 2000; 1: 15-22

Dormehl S, Robertson S, Williams C. Modelling the progression of male swimmers' performances through adolescence. Sports, 2016; 4: 2 
Garrido N, Marinho DA, Barbosa TM, Costa AM, Silva AJ, Pérez-Turpin JA, Marques MC. Relationships between dry land strength, power variables and short sprint performance in young competitive swimmers. J Hum Sport Exerc, 2010; 5: 240-249

Garrido N, Silva AJ, Fernandes RJ, Barbosa TM, Costa AM, Marinho D, Marques MC. High level swimming performance and its relation to non-specific parameters: A cross-sectional study on maximum handgrip isometric strength. Percept Mot Skills, 2012; 114: 936-948

Gatta G, Cortesi M, Di Michele R. Power production of the lower limbs in flutter-kick swimming. Sport Biomech, 2012; 11: 480-491

Gourgoulis V, Boli A, Aggeloussis N, Toubekis A, Antoniou P, Kasimatis P, Vezos N, Michalopoulou M, Kambas A, Mavromatis G. The effect of leg kick on sprint front crawl swimming. J Sports Sci, 2014; 32: 278-289

Hawley JA, Williams MM. Relationship between upper body anaerobic power and freestyle swimming performance. Int J Sports Med, 1991; 12: 1-5

Hawley JA, Williams MM, Vickovic MM, Handcock PJ. Muscle power predicts freestyle swimming performance. Br J Sports Med, 1992; 26: 151-155

Hopkins WG. A Scale of Magnitudes for Effect Statistics. A New View Stat, 2002. Available at: http://www.sportsci.org/resource/stats/effectmag.html

Inbar O, Bar-Or O, Skinner JS. The Wingate Anaerobic Test. Human Kinetics, 1996

Kalva-Filho C, Zagatto A, da Silva A, Castanho M, Gobbi R, Gobatto C, Papoti M. Relationships among the Tethered 3-min All-Out Test, MAOD and Swimming Performance. Int J Sports Med, 2017; 38: 353-358

Keiner M, Yaghobi D, Sander A, Wirth K, Hartmann H. The influence of maximal strength performance of upper and lower extremities and trunk muscles on different sprint swim performances in adolescent swimmers. Sci Sports, 2015; 30: e147-e154

Lawrence L. The importance of the freestyle leg kick. Int Swim, 1969; 5: 11-12

Lipinska P, Hopkins WG. Pacing profiles and competitive performance of elite female 400-m freestyle swimmers. J Strength Cond Res, 2017: 1

Loturco I, Barbosa AC, Nocentini RK, Pereira LA, Kobal R, Kitamura K, Abad CCC, Figueiredo P, Nakamura FY. A correlational analysis of tethered swimming, swim sprint performance and dry-land power assessments. Int J Sports Med, 2016; 37: 211-218

Mitchell LJG, Rattray B, Saunders PU, Pyne DB. The relationship between talent identification testing parameters and performance in elite junior swimmers. J Sci Med Sport, 2018; 21: 1281-1285

Mooney R, Quinlan LR, Corley G, Godfrey A, Osborough C, ÓLaighin G. Evaluation of the Finis Swimsense ${ }^{\circledR}$ and the Garmin Swim ${ }^{\mathrm{TM}}$ activity monitors for swimming performance and stroke kinematics analysis. PLoS One, 2017; 12: 1-17

Morais JE, Marinho DA, Arellano R, Barbosa TM. Start and turn performances of elite sprinters at the 2016 European Championships in swimming. Sport Biomech, 2019; 18: 100-114

Morais JE, Silva AJ, Garrido ND, Marinho DA, Barbosa TM. The transfer of strength and power into the stroke biomechanics of young swimmers over a 34-week period. Eur J Sport Sci, 2018; 18: 787-795

Morouço PG, Marinho D a, Keskinen KL, Badillo JJ, Marques MC. Tethered swimming can be used to evaluate force contribution for short-distance swimming performance. J Strength Cond Res, 2014; 28: 3093-3099

Morouço PG, Marinho DA, Izquierdo M, Neiva H, Marques MC. Relative contribution of arms and legs in front 30 s fully tethered front crawl swimming. Biomed Res Int, 2015; 2015: 67

Morouço PG, Neiva H, González-Badillo JJ, Garrido N, Marinho DA, Marques MC. Associations between dry land strength and power measurements with swimming performance in elite athletes: a pilot study. J Hum Kinet, 2011: 105-112

Morris KS, Osborne MA, Shephard ME, Skinner TL, Jenkins DG. Velocity, aerobic power and metabolic cost of whole body and arms only front crawl swimming at various stroke rates. Eur J Appl Physiol, 2016; 116: $1075-1085$

Neiva HP, Dias P, Marinho DA. The effect of training on aerobic and anaerobic critical velocities in young swimmers. Int Phys Med Rehabil J, 2019; 4: 96-100 
Olstad BH, Zinner C, Vaz JR, Cabri JMH, Kjendlie PL. Muscle activation in world-champion, world-class, and national breaststroke swimmers. Int J Sports Physiol Perform, 2017; 12: 538-547

Perez-Olea J, Valenzuela P, Aponte C, Izquierdo M. Relationship between dryland strength and swimming performance: pull-up mechanics as a predictor of swimming speed. J Strenght Cond Res, 2018; 32: 16371642

Prins J, Murata N. Kinematic analysis of swimmers with permanent physical disabilities. Int J Aquat Res Educ, 2008; 2: 330-345

Rohrs DM, Stager JM. Evaluation of anaerobic power and capacity in competitive swimmers. J Swim Res, 1991; 7: 12-16

Santos M, Junior M, Melo Wv, Costa A, Costa M. Estimate of propulsive force in front crawl swimming in young athletes. Open Access J Sport Med, 2012; 3: 115-120

Sharp R, Costill D. Force, work, and power: What they mean to the competitive swimmer. Swim World, 1982; 23: $41-43$

Stager JM, Coyle MA. Energy Systems. In: Handbook of Sports Medicine and Science: Swimming. Oxford: Blackwell Science Ltd, 1-19, 2005

Strzała M, Stanula A, Głąb G, Głodzik J, Ostrowski A. Shaping physiological indices, swimming technique, and their influence on 200m breaststroke race in young swimmers. J Sport Sci Med, 2015: 110-117

Strzała M, Stanula A, Krężałek P, Ostrowski A, Kaca M, Głąb G. Influence of morphology and strength on front crawl swimming speed in junior and youth age-group swimmers. J Strength Cond Res, 2019; 33: 2836-2845

Strzała M, Stanula A, Krężałek P, Sadowski W, Wilk R, Pałka T, Sokołowski K, Radecki-Pawlik A. Body composition and specific and general strength indices as predictors of 100-m front crawl performance. Acta Bioeng Biomech, 2020; 22: 1-19

Strzała M, Stanula A, Ostrowski A, Kaca M, Krężałek P, Głodzik J. Propulsive limb coordination and body acceleration in sprint breaststroke swimming. J Sports Med Phys Fitness, 2017; 57: 1564-1571

Strzała M, Tyka A. Physical endurance, somatic indices and swimming technique parameters as determinants of front crawl swimming speed at short distances in young swimmers. Med Sport, 2009; 13: 99-107

Tanner RK, Gore CJ. Physiological Tests for Elite Athletes. 2nd ed. Lower Mitcham, South Australia: Human Kinetics, Inc., 2013

Veiga S, Roig A, Gómez-Ruano MA. Do faster swimmers spend longer underwater than slower swimmers at World Championships? Eur J Sport Sci, 2016; 16: 919-926

Vorontsov AR, Dyrco V V., Binevsky DA, Solomatin VR. Patterns of growth for some characteristics of physical development, functional and motor abilities in boy-swimmers 11-18 years. In: Keskinen KL, Komi P V., Hollander AP (eds) Biomechanics and Medicine in Swimming VIII. Jyväskylä: University of Jyväskylä, 327-335, 1999

Wadrzyk L, Staszkiewicz R, Zeglen M, Kryst L. Relationship between somatic build and kinematic indices of underwater undulatory swimming performed by young male swimmers. Int J Perform Anal Sport, 2021

Washino S, Mayfield DL, Lichtwark GA, Mankyu H, Yoshitake Y. Swimming performance is reduced by reflective markers intended for the analysis of swimming kinematics. J Biomech, 2019; 91: 109-113

Watkins J, Gordon AT. The effect of leg action on performance in the sprint front crawl stroke. Biomech Med Swim, 1982: 310-314

West DJ, Owen NJ, Cunningham DJ, Cook CJ, Kilduff LP. Strength and power predictors of swimming starts in international sprint swimmers. J Strength Cond Res, 2011; 25: 950-955

\section{Corresponding author:}

Arkadiusz Stanula

Department of Swimming and Water Rescue; Institute of Sport Sciences, The Jerzy Kukuczka Academy of Physical Education, Katowice, Poland

40-065 Katowice, Mikołowska 72A

Tel./fax: +48 32207 5333, mobile: +48 504124 470; E-mail address: a.stanula@awf.katowice.pl 